\title{
Association Between the Presence of Intrauterine Escherichia Coli Virulence Genes and Subsequent Reproductive Tract Disease in Postpartum Dairy Cows
}

\author{
José Denis-Robichaud, John Morris Fairbrother, Flavien Ndongo Kassé, and Jocelyn Dubuc* \\ Université de Montréal, Faculté de médecine Vétérinaire, St-Hyacinthe, Québec, Canada
}

*Corresponding author: Jocelyn Dubuc, Faculté de médecine vétérinaire, Université de Montréal, rue Sicotte, St-Hyacinthe, Québec, Canada

\begin{abstract}
An association between postpartum intrauterine Escherichia coli and subsequent reproductive tract diseases such as purulent vaginal discharge (PVD) and endometritis (ENDO) has been found inconsistently in previous research. This inconsistency may be due to differences in the pathogenicity and presence of certain virulence factors in the various strains. The objective of this study was to evaluate the association between the presence of intrauterine $E$. coli virulence factor (VF) genes after parturition and subsequent reproductive tract diseases in postpartum dairy cows. Intrauterine swabs were collected from cows 4 ( \pm 3 ) DIM. The swabs were plated to identify E. coli, Trueperella pyogenes, Fusobacterium necrophorum, and Prevotella melaninogenica. A subgroup of the E. coli samples was submitted for colony hybridization for identification of $40 \mathrm{VF}$ genes. Purulent vaginal discharge and ENDO were diagnosed at $35( \pm 7)$ DIM using the Metricheck device (purulent discharge or worse) and the cytobrush technique adapted for use in cattle ( $\geq 6 \%$ polymorphonuclear leukocytes), respectively. Cows diagnosed with PVD, ENDO, or both conditions were classified as positive for reproductive tract disease. Logistic regression models were built using the reproductive tract disease status as the outcome, and the bacteria and VF gene presence as the exposure. Of the 465 cows enrolled, $52 \%$ of the uterine samples were positive for E. coli, 34\% were positive for T. pyogenes, $3 \%$ were positive for F. necrophorum, and $1 \%$ were positive for $P$. melaninogenica. A total of 152 E. coli samples were examined for VF gene identification. Reproductive tract disease was diagnosed in 237 cows (51\%). The presence of intrauterine E. coli and T. pyogenes was associated with greater odds of reproductive tract disease. Cows with E. coli positive for VF genes fepC, maIX, hlyE, sitA, irp1, irp2, fyuA, or iss had greater odds of having subsequent reproductive tract disease compared to cows without $E$. coli. These VF genes code for iron acquisition, the maltose and glucose PTS system, hemolysin E toxin, and increased serum survival. Three of the siderophore genes (irp1, irp2, and fyuA) are part of the core of a high-pathogenicity islands, previously described in extraintestinal pathogenic E. coli (ExPEC) The results of this study suggest that certain VFs are likely to contribute to the pathogenicity of $E$. coli strains as they are associated with subsequent reproductive tract disease.
\end{abstract}

Keywords: Endometritis; High-Pathogenicity Island; Purulent Vaginal Discharge; Siderophore

\section{Introduction}

Purulent vaginal discharge (PVD) and endometritis (ENDO) are reproductive tract diseases diagnosed in postpartum dairy cows and are associated with a detrimental impact on subsequent reproductive performance [1-3]. The diagnosis of PVD is based on the presence of purulent material in the vagina visualized using devices such as the Metricheck or a vaginoscope [4-6]. The diagnosis of ENDO is based on the presence of an excessive proportion of inflammatory cells on an endometrial smear obtained with a cytobrush or a low-volume uterine lavage [7]. Risk factors for PVD and ENDO are dystocia, retained placenta, postpartum metritis, as well as negative energy balance $[4,8,9]$, suggesting that both the immunity of the cow and the presence of intrauterine bacteria shortly after parturition play a role in the later development of these reproductive diseases. However, intrauterine bacteria such as 
Escherichia coli, Trueperella pyogenes, Fusobacterium necrophorum, and Prevotella melaninogenica are associated inconsistently with endometrial inflammation and clinical disease [10-12]. Research suggests that the association between the presence of different bacteria and reproductive tract disease depends on the moment of sampling, due to the dynamic nature of the infections $[13,14,11]$. Whereas the presence of intrauterine $T$. pyogenes during the first month postpartum was associated with PVD and endometritis, the association between E. coli during the first month postpartum and these diseases is not as clear $[13,14,11]$.

A variety of strains of $E$. coli with differing pathogenicity have been found, possibly explaining the inconsistent association between the intrauterine presence of this bacterium and the subsequent development of reproductive tract disease $[15,16]$. Intrauterine $E$. coli has been characterized by the identification of virulence factor (VF) genes [17,13,18]. Bicalho, et al. [13] found an association between the presence of certain VF genes (fimH, cdt and astA) and PVD. Dubuc et al. [9] showed however, that cows without PVD can have endometritis, and vice versa, which could bias the associations between risk factors and disease toward the null hypothesis if a proportion of the cows classified as healthy also have reproductive tract disease [19]. The objective of this study was to evaluate the association between the presence of intrauterine E. coli, and E. coli VF genes after parturition and subsequent reproductive tract disease (PVD, ENDO, or both) in postpartum dairy cows.

\section{Materials and Methods}

This study was originally designed to identify associations between E. coli VF genes and postpartum metritis (PPM), as reported by as reported elsewhere [18]. In this work, Holstein dairy cows from 4 commercial farms located within $30 \mathrm{~km}$ of the bovine ambulatory clinic of the Faculté de médecine vétérinaire, Université de Montréal (Saint-Hyacinthe, QC, Canada) were enrolled on a prospective cohort study from November 2011 to June 2012. Farms were a convenient sample of freestall housed herds using computerized health records, and enrolled in a biweekly herd health veterinary program. During the study period, all cows that did not yet show clinical signs of PPM were enrolled weekly (at $4 \pm 3$ DIM). The sample size was calculated for the original study [18], to identify a $20 \%$ difference in PPM prevalence with $95 \%$ confidence and $80 \%$ power [19]. Procedures were approved by the animal care committee of the Université de Montréal [11-Rech-1605]. At enrolment, cows were sampled to identify uterine bacteria. Briefly, cows were restrained and the perineum was cleaned and disinfected with 70\% ethyl alcohol solution (Isopropylic Alcohol 70\% USP; Green Field Inc., Brampton, ON, Canada). A sterile double-guarded uterine swab (Guarded culture swab; Jorvet Inc., Loveland, CO, US) was introduced in the cranial vagina then passed through the cervix until the body of the uterus. The swab was then exposed to the dorsal aspect of the uterine wall. The swab was placed in an anaerobic transportation medium (BBL Port-A-Cult Tubes; Becton, Dickinson and Company, Sparks, MD, US) and kept at $4^{\circ} \mathrm{C}$ until submission to the veterinary diagnostic laboratory of the Université de Montréal within $12 \mathrm{~h}$ of collection.
Escherichia coli, T. pyogenes, $F$. necrophorum, and $P$. melaninogenica were identified from the uterine swab in the veterinary diagnostic laboratory of the Université de Montréal (Saint-Hyacinthe, QC, Canada), as described by as reported elsewhere [18]. Briefly, swabs were plated on blood agar and MacConkey agar (Oxoid) at $37^{\circ} \mathrm{C}$ for isolation of E. coli. Five isolates from each positive sample were submitted to indole spot, Simmons citrate, and motility tests, for confirmation of E. coli. Escherichia coli isolates were stored in tryptic soy broth containing 30\% glycerol at $-80^{\circ} \mathrm{C}$ (Becton, Dickinson and Company) for further analysis. Swabs were also plated on Colombia blood agar (Oxoid, Ottawa, ON, Canada) at $35^{\circ} \mathrm{C}$ for $48 \mathrm{~h}$ for isolation of T. pyogenes using the PONBAC-019 procedure (beta-hemolytic, catalase-negative minuscule colonies demonstrating gram-positive coryneform rods; [20]). A subgroup of the $E$. coli isolates was examined by colony hybridization using radioactively labeled (32P) DNA probes for identification of VF genes at the World Organisation for Animal Health Reference Laboratory for Escherichia coli (Faculté de médecine vétérinaire, Université de Montréal; [21,22]. Briefly, the isolates were spotted onto Luria-Bertani agar and incubated at $37^{\circ} \mathrm{C}$ overnight. Colonies were then transferred to Whatman 541 filter paper (Whatman, Piscataway, NJ, US). The filter papers were processed, hybridized, and visualized by autoradiography. Probes were derived from E. coli control strains by uniplex PCR, using the primers of the tested genes. After amplification, PCR products were purified and concentrated, using the QIAquick PCR Purification Kit (Qiagen, Hilden, Germany) according to manufacturer's instructions. After purification, probes were marked with phosphate 32 using a specific kit (Amersham Ready to go DNA Labeling Beads, GE Healthcare UK Limited, Little Chalfont, UK), according to the manufacturer's instructions. All isolates ( 5 per sample) submitted for colony hybridization were tested for $40 \mathrm{VF}$ genes (complete list in Appendix A1).

Postpartum metritis was diagnosed and recorded between calving and 21 DIM by one person per farm. The standardized definition was reviewed with participating farmers before the beginning and every 3 mo during the study: fetid watery red-brown uterine discharge, associated with fever (rectal temperature > $39.5^{\circ} \mathrm{C}$ ), and systemic signs of illness (dullness, reduced appetite, and milk production) [11]. When PPM was diagnosed, cows were treated with $5 \mathrm{~d}$ of ceftiofur IM SID $(2.2 \mathrm{mg} / \mathrm{kg}$; Zoetis Animal Health, Kirkland, QC, Canada). Purulent vaginal discharge and ENDO were diagnosed biweekly at $35( \pm 7)$ DIM. Firstly, the vaginal discharge score was assessed using the Metricheck device $(0$ = no discharge, 1 = clear mucus, 2 = mucus with flecks of pus, 3 = mucopurulent discharge, $4=$ purulent discharge or $5=$ foul smelling discharge) [5]. Then, an endometrial cytology sample was taken using the cytobrush technique adapted for use in cattle $[23,9]$. Immediately after collection, the cytobrush was rolled on a microscope glass slide to obtain a smear. The microscope slides were stained within $12 \mathrm{~h}$ of collection with a modified WrightGiemsa stain (Hema3; Biochemical Sciences, Swedesboro, NJ) and glass coverslips were applied when dry as previously described [9]. The cytology slides were used to determine the percentage of polymorphonuclear leukocytes (PMNL) among two hundred cells (PMNL and endometrial cells) by 2 observers. Slide readers were 
blinded to on-farm findings and treatment allocation. Purulent vaginal discharge was defined as a vaginal discharge score of $\geq$ 4 , and ENDO was defined as percentage of PMNL $\geq 6 \%$ [3]. Cows diagnosed with PVD, ENDO, or both were classified as positive for reproductive tract disease.

\section{Statistical Analyses}

All analyses were performed using SAS Studio 3.6 (SAS Institute Inc., Cary, NC, US), the cow being the experimental unit. Parity $\left(1^{\text {st }}, 2^{\text {nd }}, 3^{\text {rd }}\right.$ and greater) and season of calving (winter: November to February, spring: March to June) were extracted from the computerized record system (DSAHR Inc., Saint-Hyacinthe, QC, Canada). Frequencies were calculated (PROC FREQ) for binary and categorical variables. Based on the bacteriological culture results, cows were categorized as (0) no bacteria, (1) presence of $E$. coli combined with other bacteria (T. pyogenes, F. necrophorum, or $P$. melaninogenica), (2) presence of a E. coli alone, or (3) presence of other bacteria (T. pyogenes, F. necrophorum, or P. melaninogenica) only. The same categories ( 0 to 3 ) were also created for T. pyogenes, F. necrophorum, and P. melaninogenica. Based on the bacteriological culture and the colony hybridization results, cows were also classified as (0) negative for E. coli, (1) positive for E. coli but negative for the VF gene, or (2) positive for E. coli and for the VF gene. Logistic regression models (PROC GLIMMIX) were built using the reproductive tract disease status as the outcome to assess its association with the presence of different intrauterine bacteria, and with the presence of $E$. coli VF genes. Herd was included in all models as a fixed effect for accounting for clustering, and parity and season were included as confounders if their P-value was > 0.20 [24]. Models were presented if statistical significance $(\mathrm{P}<$ $0.05)$ or tendency to significance $(0.05 \leq \mathrm{P}<0.10)$ was reached. The difference between parameters of a categorical variable was assessed using Tukey-Kramer adjustment for multiple comparisons (P), using $<0.05$ for statistical significance and 0.05 to 0.10 for tendency to significance. The Hosmer and Lemeshow goodness-offit test was used to assess the fit of the models. Outlier (Pearson and deviance residuals), extreme (hat matrix), and influential (DFBeta) covariate patterns were assessed, and models were tested without extreme and influential values to ensure robustness of the coefficients [19].

\section{Results}

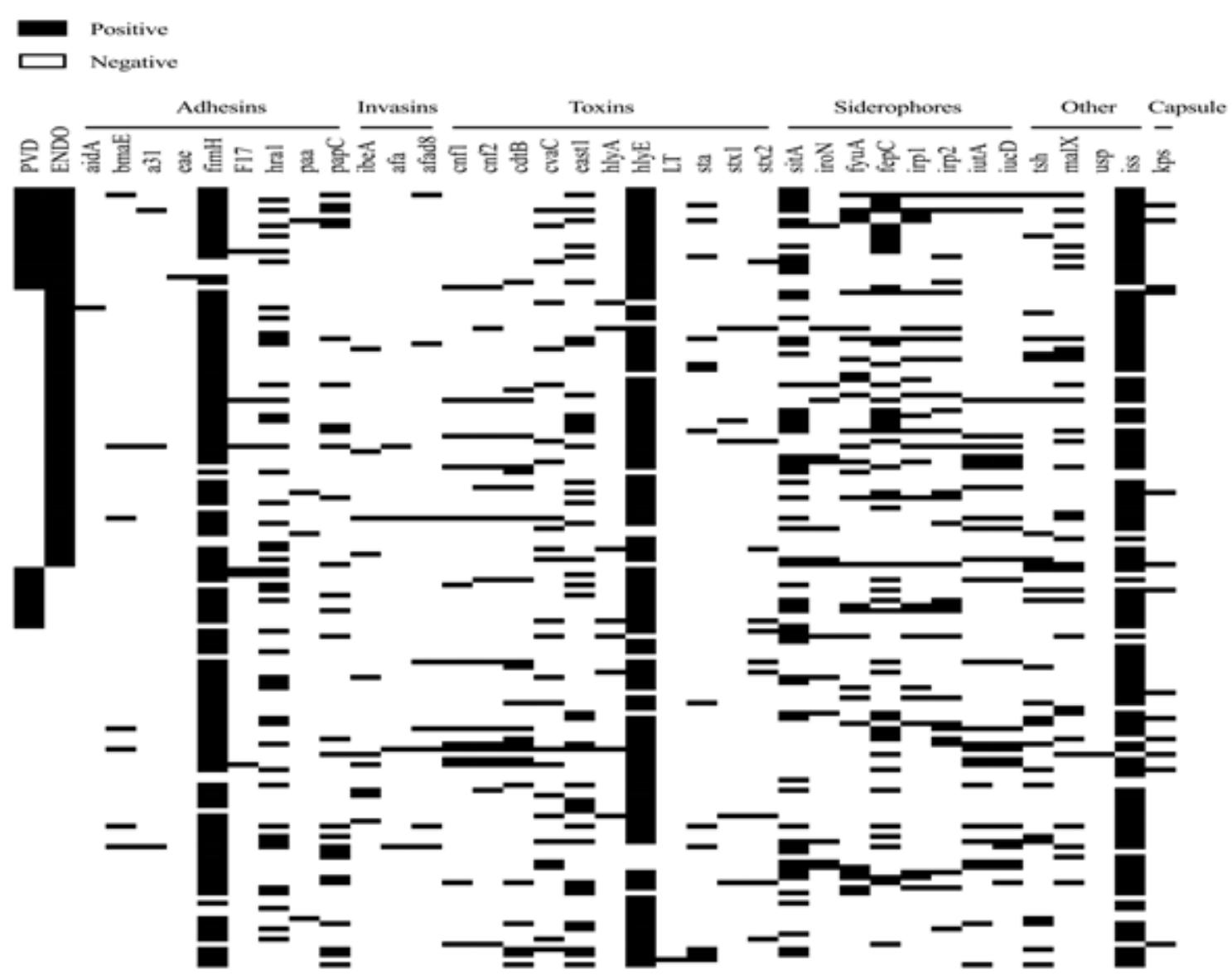

Figure 1: Presence of 36 virulence factor genes in intrauterine Escherichia coli isolates from 152 Holstein dairy cows sampled $4 \pm 3$ DIM. Cows' profiles are sorted by reproductive tract disease status at $35 \pm 7$ DIM (vaginal purulent discharge: PVD, endometritis: ENDO). 
A total of 486 cows were enrolled in this study from 4 freestall commercial farms $(141,177,136$, and 32 samples from farms 1,2 , 3 , and 4 , respectively). A total 465 cows remained for final analyses as 21 (4\%) were culled before the diagnosis of reproductive tract diseases at 35 DIM. Thirty-four percent ( $\mathrm{n}=160), 32 \%(\mathrm{n}=148)$, and $34 \%$ ( $n=157$ ) of the remaining cows were of 1 st, $2 n d$, and 3rd and greater parity, respectively. Forty-two percent $(n=194)$ of the cows calved during spring, and 58\% $(\mathrm{n}=271)$ calved during winter. Overall, 243 (52\%) of the uterine samples were positive for E. coli, 156 (34\%) were positive for T. pyogenes, 16 (3\%) were positive for F. necrophorum, and 3 (1\%) were positive for P. melaninogenica. A total of 780 isolates from 152 of the samples positive for $E$. coli were submitted for hybridization to identify VF genes. A visual summary of the $36 \mathrm{VF}$ genes found in the uterine $E$. coli of cows is presented in Figure 1. A total of 133 different cow VF profiles were identified, with 1 to $16 \mathrm{VF}$ per profile. The most prevalent VF genes were hlyE ( $n=135 ; 89 \%$ cows harboring one or more positive isolates) and fimH ( $n=133 ; 88 \%$ cows harboring one or more positive isolates), coding for hemolysin and adherence, respectively. Postpartum metritis was diagnosed in 65 cows (14\%), and reproductive tract diseases were diagnosed in 237 cows (51\%), of which 32 (7\%) had PVD, 136 (29\%) had endometritis, and 69 (15\%) had both PVD and endometritis.

Table 1 presents the odds of reproductive tract diseases in cows without intrauterine bacteria, and with different profiles of E. coli, T. pyogenes, F. necrophorum, and P. melaninogenica. Virulence factor genes fepC, maIX, hlyE, and sitA were associated with a harmful effect and VF gene cdtB with a protective effect for reproductive tract disease (Figure 2). Cows harboring isolates positive for fepC had 2.62 times the odds of having reproductive disease compared to cows without E. coli (95\% CI = 1.26-5.45; P = 0.01), and 2.09 times the odds of having reproductive disease compared to cows with E. coli but without the fepC $(95 \% \mathrm{CI}=0.95-4.62 ; \mathrm{P}=0.07)$. Cows harboring isolates positive for maIX had 2.99 times the odds of having reproductive disease compared to cows without $E$. coli (95\% CI = 1.20-7.43; $\mathrm{P}=0.02$ ), and 2.25 times the odds of having reproductive tract disease compared to cows with $E$. coli but without the maIX $(95 \% \mathrm{CI}=0.87-5.80 ; \mathrm{P}=0.09)$. Cows harboring isolates positive for hlyE and sitA had 1.72 (95\% CI = 1.10-2.69; $\mathrm{P}=0.04)$, and $2.13(95 \% \mathrm{CI}=1.14-3.97 ; \mathrm{P}=0.02)$ times the odds of having reproductive tract disease compared to cows without $E$. coli, respectively. Cows with $E$. coli but without VF gene cdtB were 1.80 times more likely to have reproductive tract disease than cows without $E$. coli $(95 \% \mathrm{CI}=1.14-2.83 ; \mathrm{P}=0.01)$, and cows harboring $E$. coli positive for cdtB had 0.41 times the odds of having reproductive tract disease compared to cows with $E$. coli and without cdtB (95\% $\mathrm{CI}=0.16-1.05 ; \mathrm{P}=0.06$ ). Logistic regression models for irp1, irp2, fyuA, and iss had a tendency to be statistically significant, but there was a significant difference in the odds of reproductive tract disease between cows harboring E. coli positive for these VF genes and cows without $E$. coli $(\mathrm{P}<0.05)$. Cows harboring $E$. coli positive for irp1, irp2, fyuA, and iss had 3.62 (95\% CI = 1.10-11.90; $\mathrm{P}=0.03$ ), $2.51(95 \% \mathrm{CI}=1.01-6.24 ; \mathrm{P}=0.05), 2.69(95 \% \mathrm{CI}=1.01-7.18 ; \mathrm{P}=$ $0.05)$, and $1.69(95 \% \mathrm{CI}=1.08-2.64 ; \mathrm{P}=0.02)$ times the odds of having reproductive tract diseases compared to cows without $E$. coli, respectively.

Table 1: Odds of reproductive tract disease at 35 \pm 7 DIM (purulent vaginal discharge, endometritis, or both) from logistic regression models in 465 Holstein dairy cows with different profiles of uterine bacterial status at $4 \pm 3$ DIM, adjusted for herd clustering.

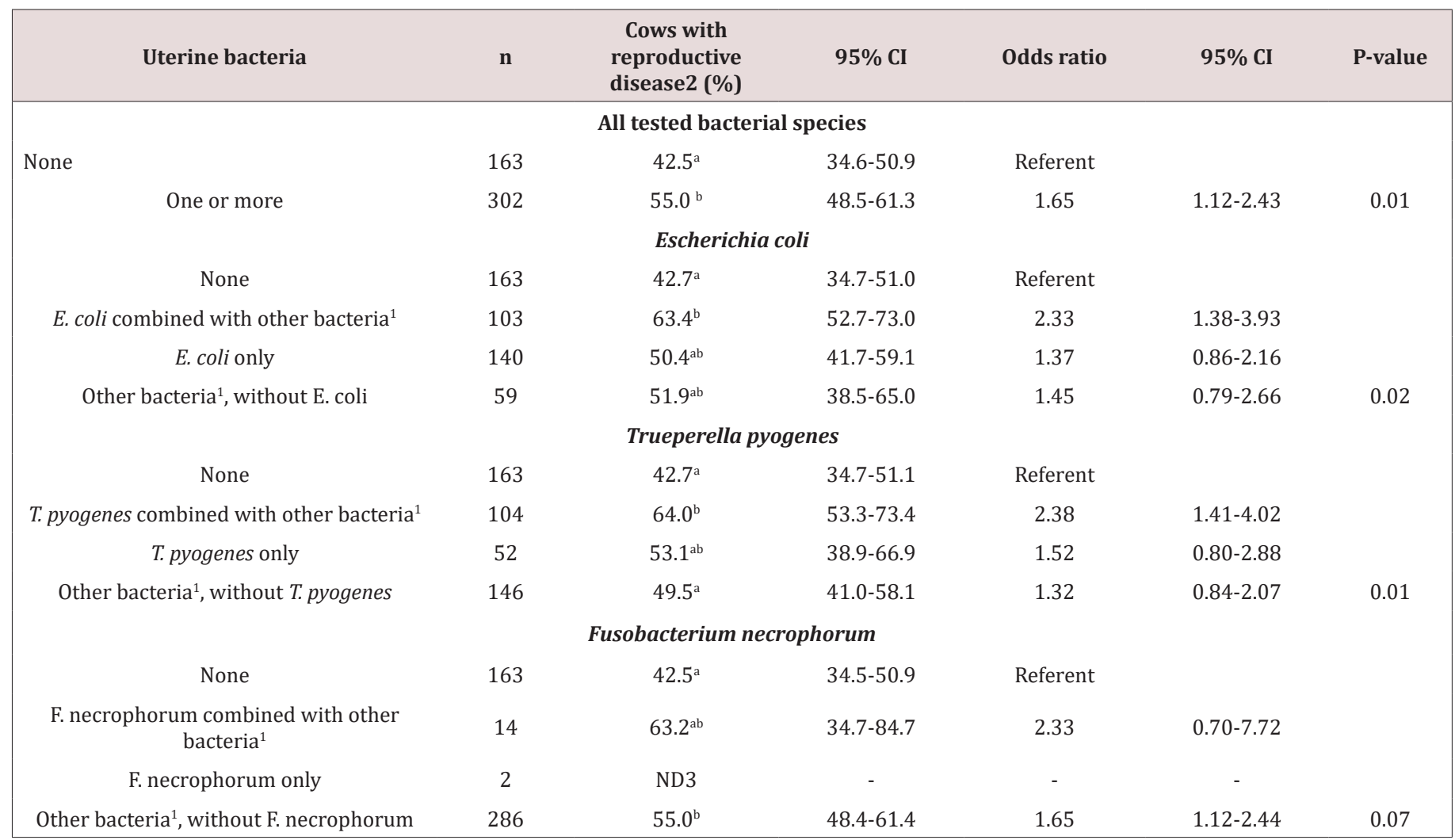




\begin{tabular}{|c|c|c|c|c|c|c|}
\hline \multicolumn{7}{|c|}{ Prevotella melaninogenica } \\
\hline None & 163 & $42.5^{\mathrm{a}}$ & $34.6-50.9$ & Referent & & \\
\hline $\begin{array}{l}\text { P. melaninogenica combined with other } \\
\text { bacteria }^{1}\end{array}$ & 3 & ND3 & - & - & - & \\
\hline Other bacteria ${ }^{1}$, without $P$. melaninogenica & 299 & $54.9^{\mathrm{b}}$ & 48.4-61.3 & 1.65 & $1.12-2.43$ & 0.04 \\
\hline
\end{tabular}

${ }^{a-b}$ Means within a column within a model with different subscripts differ, assessed using Tukey-Kramer adjustment for multiple comparisons $\left(\mathrm{P}_{\mathrm{TK}}<0.05\right)$.

${ }^{1}$ Other bacterial species were Escherichia coli, Trueperella pyogenes, Fusobacterium necrophorum, and Prevotella melaninogenica

${ }^{2}$ Estimated population marginal proportion (LSM) of cows with reproductive diseases at 35 \pm 7 DIM (purulent vaginal discharge, endometritis, or both)

${ }^{3} \mathrm{ND}$ : not determined due to small $\mathrm{n}$

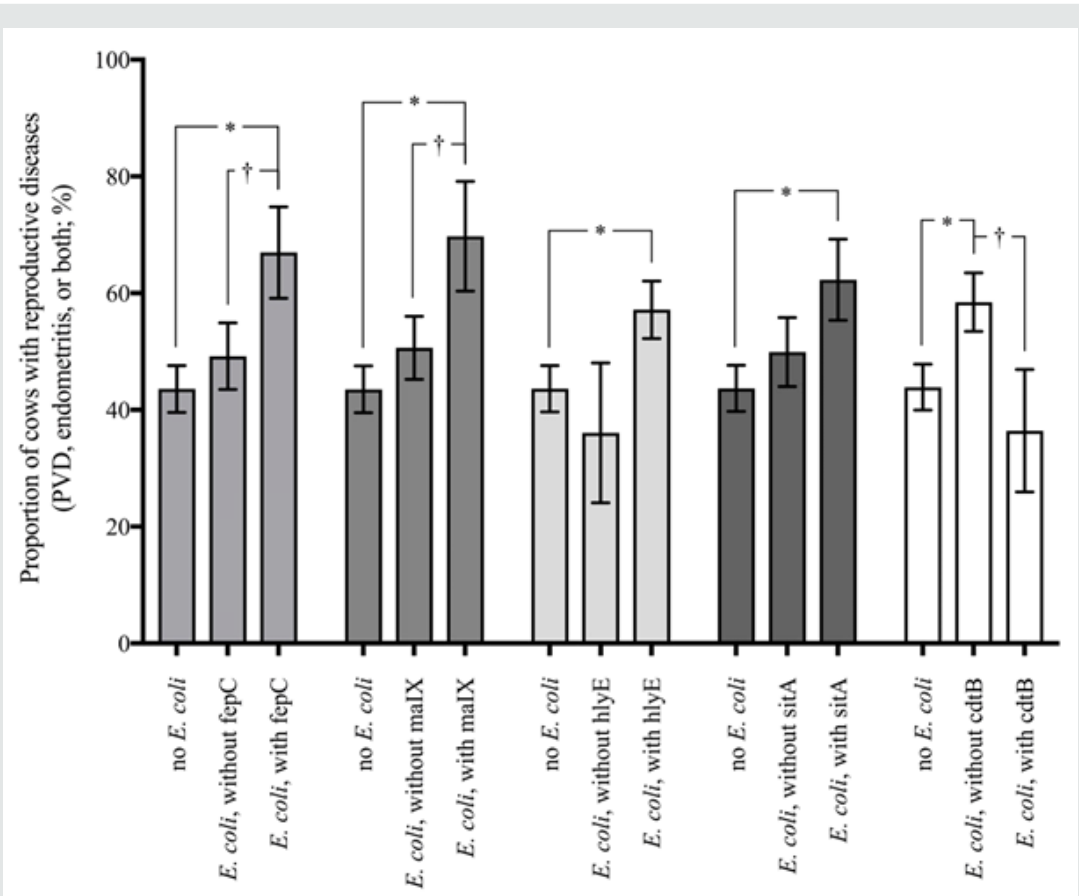

Figure 2: Proportion of cows with reproductive tract disease (purulent vaginal discharge, endometritis, or both) at $35 \pm 7$ DIM stratified by uterine bacteriological status at $4 \pm 3$ DIM in 374 Holstein dairy cows. The marginal means $( \pm$ SEM) were obtained from logistic regression models (one per virulence factor gene), adjusted for herd clustering using a Tukey-Kramer adjustment for multiple comparisons. The virulence factor genes fepC, maIX, hlyE, and sitA were identified as harmful, and the virulence factor gene cdtB was identified as protective for reproductive diseases. ${ }^{*} P_{\mathrm{TK}}<0.05 . \dagger P_{\mathrm{TK}}<0.10$.

\section{Discussion}

As the presence of postpartum intrauterine E. coli was inconsistently associated with reproductive tract diseases in dairy cows $[13,14,11]$, the objective of the present study was to assess the association of reproductive tract diseases such as PVD and ENDO with the presence of intrauterine bacteria during the first week postpartum of dairy cows, and more specifically the presence of E. coli $\mathrm{VF}$ genes. When compared to cows without intrauterine $E$. coli, cows with genes for iron acquisition (fepC, sitA, irp1, irp2, and fyuA), for maltose and glucose PTS system (malX), for hemolysin E toxin (hlyE), and for increased serum survival (iss) had greater odds of presenting reproductive disease. As observed for urinary infection, meningitis, and septicemia in humans, the E. coli involved in reproductive tract disease require characteristics allowing them to survive outside of the intestinal environment. Iron acquisition factors are often associated with extraintestinal pathogenic E. coli (ExPEC) as they contribute to the survival of the bacteria in an environment where iron is not readily available [25]. Moreover, it was suggested that siderophores also had a cytotoxic effect on immune cells $[26,27]$. In the present study, five siderophore genes were associated with increased odds of reproductive tract diseases, of which three (irp1, irp2, and fyuA) are part of the core of the high-pathogenicity islands (HPI). First described in pathogenic Yersinia, HPI results from an accumulation of virulence factors on the bacterial chromosome and have been identified in pathogenic ExPEC, suggesting that they contribute to the survival and pathogenicity of bacteria [27-29]. Septicemia and pelvic inflammatory disease in cattle have been associated with $E$. coli positive for the HPI and fyuA genes, respectively [16,28], but the present study was the first to demonstrate an association between reproductive tract disease and fyuA, irp1 and irp2 genes. 
In the present study, both malX and iss were also associated with increased odds of reproductive tract disease. These two factors play a role the survival of ExPEC outside of the intestinal environment. malX is mainly considered as a marker for pathogenicity as its codes for an enzyme system that does not contribute to the virulence of a bacteria but has been associated with other virulence genes [30-32]. It was, however, found in persistent $E$. coli strains which suggested that the malX gene may also have an additive or synergetic effect with respect to pathogenicity islands [32]. Similarly, iss contributes to the survival of the bacteria against host immunity affecting the complement system [33] but was mainly associated with other virulence factors [34,35]. Our finding of an association between reproductive tract disease and pathogenicity markers such as malX and iss suggests that the impact of intrauterine $E$. coli is influenced by the VFs of the bacteria, possibly explaining the inconsistent results previously found [10-12]. The eight factors associated with reproductive tract diseases in the present study were different from those found previously by Bicalho et al. [12]; fimH, cdt, and astA). Whereas Bicalho et al. [13] examined the association between the VFs and PVD, reproductive tract diseases in the present study were defined as either PVD, ENDO, or both. In studies looking at both PVD and ENDO, 10 to $26 \%$ of the cows were negative for PVD and positive for ENDO [2,3], which could have contributed to the different results between studies. It is not clear why, in the present study, the presence of $E$. coli harboring the cdtB gene was associated with lower odds of reproductive disease than the presence of $E$. coli without this gene or the absence of $E$. coli. A possible explanation is that the analyses did not account for a confounder when assessing the association between the presence of a gene and reproductive disease [19]. For example, if the presence of cdtB gene was associated with an unmeasured variable that reduces the odds of reproductive disease, the protective effect of this gene would be the eventual consequence.

In the present study, bacterial culture was used to identify four bacterial species (E. coli, T. pyogenes, F. necrophorum, and $P$. melaninogenica). The prevalence of cows with intrauterine bacteria of these species was lower than in other studies looking at the presence of intrauterine bacteria where more or different bacterial species were identified [36,37]. Wagener et al. [11] found a prevalence of intrauterine bacteria of $80 \%$ at 3 DIM, although Streptococcus uberis, which we did not look for, was present alone in $18 \%$ of the cows. In the present study, it is possible that the association between the presence of intrauterine bacteria and reproductive tract disease was biased toward the null hypothesis due to the presence of other bacterial species in the cows we classified as negative to intrauterine bacteria. For example, the presence of $S$. uberis at 3 DIM was associated with greater odds of PVD [11]. Similarly, metagenomic analysis has the potential to identify uncultivable bacteria [38], which could give rise to different findings with respect to the association between the presence of intrauterine bacteria and reproductive tract diseases. The prevalence of reproductive disease in the cows classified as negative for intrauterine bacteria was greater than $40 \%$ in our study, which could partly be explained by the limited number of bacterial species that we looked for, as well as the point in time that the uterine sample was taken. Recent studies showed the dynamic nature of the intrauterine bacterial population $[13,14,11]$, which was not evaluated in the present study as only one sample was taken shortly after calving. Finally, the prevalence of reproductive tract disease in cows without intrauterine bacteria was $42.5 \%$, which supports the idea that even though bacteria and their VFs are playing a role in the development of the disease, other factors are likely involved $[8,39]$.

\section{Conclusion}

This study showed that the presence of intrauterine $E$. coli with genes for siderophores or HPI during the first week postpartum in dairy cows was associated with greater odds of reproductive tract disease. Some of these genes have previously been shown to co-exist in ExPEC and possibly contribute to the survival of $E$. coli in the reproductive tract. These findings support the idea that peripartum bacterial contamination has an impact on subsequent health of the reproductive tract, and that it is possible to identify more accurately the bacteria involved using VFs.

\section{Acknowledgement}

The data used in the present study were retrieved from a research project funded by "Le Ministère de l'Agriculture, des Pêcheries et de l'Alimentation du Québec- Programme Innov'Action" (Québec, QC, Canada) with a research grant attributed to Jocelyn Dubuc (810144). The authors are grateful to Brigitte Lehoux, Ghyslaine Vanier, and Jean-Philippe Pelletier (Université de Montréal, StHyacinthe, QC, Canada) for their technical work during this project and to the participating dairy farmers for their willingness to enroll in this study.

\section{References}

1. Gilbert RO, ST Shin, CL Guard, HN Erb, M Frajblat (2005) Prevalence of endometritis and its effects on reproductive performance of dairy cows. Theriogenology 64: 1879-1888.

2. Dubuc J, TF Duffield, KE Leslie, JS Walton, SJ LeBlanc (2010) Definitions and diagnosis of postpartum endometritis in dairy cows. J Dairy Sci 93: 5225-5233.

3. Denis Robichaud J, J Dubuc (2015) Determination of optimal diagnostic criteria for purulent vaginal discharge and cytological endometritis in dairy cows. J Dairy Sci 98: 6848-6855.

4. LeBlanc SJ, TF Duffield, KE Leslie, KG Bateman, GP Keefe, et al. (2002) Defining and diagnosing postpartum clinical endometritis and its impact on reproductive performance in dairy cows. J Dairy Sci 85: 2223-2236.

5. McDougall S, R Macaulay, C Compton (2007) Association between endometritis diagnosis using a novel intravaginal device and reproductive performance in dairy cattle. Anim Reprod Sci 99: 9-23.

6. Barlund CS, TD Carruthers, CL Waldner, CW Palmer (2008) A comparison of diagnostic techniques for postpartum endometritis in dairy cattle. Theriogenology 69: 714-723.

7. Wagener K, C Gabler, M Drillich (2017) A review of the ongoing discussion about definition, diagnosis and pathomechanism of subclinical endometritis in dairy cows. Theriogenology 94: 21-30.

8. Hammon DS, IM Evjen, TR Dhiman, JP Goff, JL Walters (2006) Neutrophil function and energy status in Holstein cows with uterine health disorders. Vet. Immunol. Immunopathol 113: 21-29. 
9. Dubuc J, TF Duffield, KE Leslie, JS Walton, SJ LeBlanc (2010) Risk factors for postpartum uterine diseases in dairy cows. J Dairy Sci 93: 5764-5771.

10. Williams EJ, DP Fischer, DU Pfeiffer, GCW England, DE Noakes, et al. (2005) Clinical evaluation of postpartum vaginal mucus reflects uterine bacterial infection and the immune response in cattle. Theriogenology 63: 102-117.

11. Wagener K, T Grunert, I Prunner, M Ehling-Schulz, M Drillich (2014) Dynamics of uterine infections with Escherichia coli, Streptococcus uberis and Trueperella pyogenes in post-partum dairy cows and their association with clinical endometritis. Vet J 202: 527-532.

12. Bicalho MLS, FS Lima, VS Machado, EB Meira Jr, EK Ganda, et al. (2016) Associations among Trueperella pyogenes, endometritis diagnosis, and pregnancy outcomes in dairy cows. Theriogenology 85: 267-274.

13. Bicalho RC, VS Machado, MLS Bicalho, RO Gilbert, AGV Teixeira, et al. (2010) Molecular and epidemiological characterization of bovine intrauterine Escherichia coli. J Dairy Sci 93: 5818-5830.

14. Prunner I, H Pothmann, K Wagener, M Giuliodori, J Huber, et al. (2014) Dynamics of bacteriologic and cytologic changes in the uterus of postpartum dairy cows. Theriogenology 82: 1316-1322.

15. Kaper JB, JP Nataro, HL Mobley (2004) Pathogenic Escherichia coli. Nat Rev Microbiol 2: 123-140.

16. Sheldon IM, AN Rycroft, B Dogan, M Craven, JJ Bromfield, et al. (2010) Specific strains of Escherichia coli are pathogenic for the endometrium of cattle and cause pelvic inflammatory disease in cattle and mice. PLoS One 5: e9192.

17. Silva E, S Leitão, T Tenreiro, C Pomba, T Nunes, et al. (2009) Genomic and phenotypic characterization of Escherichia coli isolates recovered from the uterus of puerperal dairy cows. J Dairy Sci 92: 6000-6010.

18. Kassé FN, JM Fairbrother, J Dubuc (2016) Relationship between Escherichia coli virulence factors and postpartum metritis in dairy cows. J Dairy Sci 99: 4656-4667.

19. Dohoo IR, SW Martin, H Stryhn (2009) Veterinary Epidemiologic Research. (2 ${ }^{\text {nd }}$ Edn). VER Inc., Charlottetown, PEI, Canada.

20. McVey DS, M Kennedy, MM Chengappa (2013) Veterinary Microbiology. (3rd edn) Chapter 28, page 203. John Wiley and Sons Inc., Ames, IA.

21. Maluta RP, JM Fairbrother, AE Stella, EC Rigobelo, R Marinez, et al. (2014) Potentially pathogenic Escherichia coli in healthy, pasture-raised sheep on farms and at the abattoir in Brazil. Vet Microbiol 169: 89-95.

22. Fairbrother JH, S Dufour, JM Fairbrother, D Francoz, E Nadeau, et al. (2015) Characterization of persistent and transient Escherichia coli isolates recovered from clinical mastitis episodes in dairy cows. Vet Microbiol 176: 126-133.

23. Kasimanickam R, TF Duffield, RA Foster, CJ Gartley, KE Leslie, et al. (2004) Endometrial cytology and ultrasonography for the detection of subclinical endometritis in postpartum dairy cows. 62: 9-23.

24. Litwin CM, SB Calderwood (1993) Role of Iron in Regulation of Virulence Genes. Clin Microbiol Rev 6: 137-149.

25. Autenrieth I, K Hantke, J Heesemann (1991) Immunosuppression of the host and delivery of iron to the pathogen: a possible dual role of siderophores in the pathogenesis of microbial infections? Med Microbiol Immunol 180: 135-141.
26. Schubert S, A Rakin, H Karch, E Carniel, J Heesemann (1998) Prevalence of the "High-Pathogenicity Island" of Yersinia Species among Escherichia coli Strains That Are Pathogenic to Humans. Infect Immun 66(2): 480485 .

27. Dezfulian H, I Batisson, JM Fairbrother, PCK Lau, A Nassar, et al. (2003) Presence and Characterization of Extraintestinal Pathogenic Escherichia coli Virulence Genes in F165-Positive E. coli Strains Isolated from Diseased Calves and Pigs. J Clin Microbiol 41: 1375-1385.

28. Tourret J, M Diard, L Garry, I Matic, E Denamur (2010) Effects of single and multiple pathogenicity island deletions on uropathogenic Escherichia coli strain 536 intrinsic extra-intestinal virulence. Internat J Med Microbiol 300: 435-439.

29. Johnson JR, E Oswald, TT O’Bryan, MA Kuskowski, L Spanjaard (2002) Phylogenetic Distribution of Virulence-Associated Genes among Escherichia coli Isolates Associated with Neonatal Bacterial Meningitis in The Netherlands. J Infect Diseases 185: 774-784.

30. Johnson JR, MA Kuskowski, A Gajewski, S Soto, JP Horcajada, et al. (2005) Extended Virulence Genotypes and Phylogenetic Background of Escherichia coli Isolates from Patients with Cystitis, Pyelonephritis, or Prostatitis. J Infect Diseases 191: 46-50.

31. Östblom A, I Adlerberth, AE Wold, FL Nowrouzian (2011) Pathogenicity Island Markers, Virulence Determinants malX and usp, and the Capacity of Escherichia coli To Persist in Infants' Commensal Microbiotas. Appl Environm Microbiol 77: 2303-2308.

32. Lynne AM, JA Skyberg, CM Logue, C Doetkott, SL Foley, et al. (2007) Characterization of a Series of Transconjugant Mutants of an Avian Pathogenic Escherichia coli Isolate for Resistance to Serum Complement. Avian Diseases 51: 771-776.

33. Chuba PJ, MA Leon, A Banerjee, S Palehaudhuri (1989) Cloning and DNA sequence of plasmid determinant iss, coding for increased serum survival and surface exclusion, which has homology with lambda DNA. Mol Gen Genet 216: 287-292.

34. Johnson JR (1991) Virulence Factors in Escherichia coli Urinary Tract Infection. Clin Microbiol Rev 4: 80-128.

35. Griffin JFT, PJ Hartigan, WR Nunn (1974) Non-specific uterine infection and bovine fertility: I. Infection patterns and endometritis during the first seven weeks post-partum. Theriogenology 1: 91-106.

36. Sheldon IM, DE Noakes, AN Rycroft, DU Pfeiffer, H Dobson (2002) Influence of uterine bacterial contamination after parturition on ovarian dominant follicle selection and follicle growth and function in cattle. Reprod 123: 837-845.

37. Santos TMA, RO Gilbert, RC Bicalho (2011) Metagenomic analysis of the uterine bacterial microbiota in healthy and metritic postpartum dairy cows. 94: 291-302.

38. Sheldon IM, J Cronin, L Goetze, G Donofrio, HJ Schuberth (2009) Defining Postpartum Uterine Disease and the Mechanisms of Infection and Immunity in the Female Reproductive Tract in Cattle. Biol Reprod 81: 1025-1032.

39. An H, J M Fairbrother, C Desautels, J Harel (1999) Distribution of a novel locus called Paa (porcine attaching and effacing associated) among enteric Escherichia coli. Adv Exp Med Biol 473: 179-184. 
(c) (P)

This work is licensed under Creative

Commons Attribution 4.0 License

Submission Link: Submit Article

D0I: $10.32474 /$ CDVS.2019.02.000140

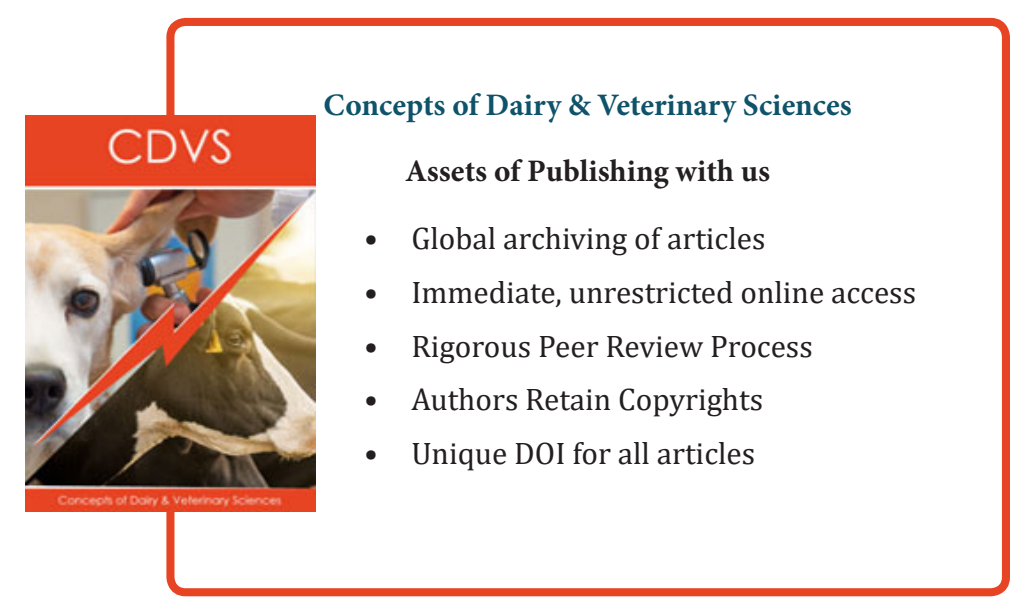

